\title{
Okul Öncesi Eğitim ve Permakültür
}

DOI: 10.26466/opus.910266

*

\author{
Sedef Cağlar Kabacık * - Ebru Deretarla Gül ** \\ * Öğretmen, MEB, Adana/Türkiye \\ E-Posta: sedefcaglar@gmail.com \\ ORCID: $\underline{0000-0002-3525-222 X}$ \\ ** Doç. Dr., Çukurova Üniversitesi, Adana/Türkiye \\ E-Posta: ebrudere@cu.edu.tr \\ ORCID: $\quad$ 0000-0002-6241-8109
}

\section{Öz}

Çocuklara erken yaşlarda verilecek permakültür eğitimi; doğa, çevre sorunları ve çözüm yolları, çevreye duyarlılık, sürdürülebilirlik vb. konularda çocukları bilinçlendirebileceği gibi onlara estetik duygular kazandırmak, fiziksel aktivite imkanı sunmak, sosyal ve duyusal gelişimlerini desteklemek, akademik (özellikle fen, matematik eğitiminde kullanılan kavramlara yönelik) başarılarını yükseltmek, alet kullanımı (tırmık, kürek, vb.) becerilerini arttırmak gibi daha pek çok alanda çocukları destekleyebileceği düşünülmektedir. Çocuklarla okul bahçelerinde, mahallelerindeki yeşil alanlarda veya evlerinin balkonlarında permakültür tasarım ilkelerini kullanarak yapılacak uygulamaların çocukların sağlıklı gıda üretme, sürdürülebilirlik konusuna dikkat çekme, günümüzdeki aşırı tüketime ve yakın çevrelerindeki sorunlardan dolayı oluşan olumsuzluklara çözümler sunabilme, toprak ve gübre üretme, hayvanların yaşam alanların iyileştirme, çocukların gelişim alanlarındaki becerilerinin desteklenmesi ve daha pek çok açıdan fayda să̆laması adına eğitimin en temel basamağı olan okul öncesi eğitim basamağına dahil edilmesi önemlidir. Ülkemizde permakültür yaklaşımına dayalı eğitim alanında özellikle de okul öncesi eğitimde akademik çalışmalara rastlanmamıştır ancak, okul öncesi, ilkokul, ortaokul, lise gibi çeşitli düzeydeki özel ve kamuya ait eğitim kurumlarının bazı permakültür içerikli projeler yaptıkları ve okul bahçelerini permakültür tasarımına yönelik dizayn ettikleri çalışmalar bulunmaktadır. Bu durum eğitim alanında farkındalı̆̆ın başladı̆̆ın fakat buna rağmen akademik çalışmalar açısından büyük bir eksikliğin olduğunu açık bir şekilde göstermiştir. Yapılan bu çalışmayla literatürdeki eksikliğin giderilmesi ve dünyada güncelliğini koruyan ülkemizde yeni yayılmaya başlayan permakültür tasarımı üzerine çalışma yapmak isteyen araştırmacılara ve eğitimcilere kaynak oluşturması amaçlanmıştır.

Anahtar Kelimeler: Okul öncesi eğitim, permakültür, sürdürülebilirlik. 


\title{
Preschool Education and Permaculture
}

$*$

\begin{abstract}
It is thought that permaculture education, when given to children at an early age, will not only raise awareness in children about nature, environmental problems and solutions, sustainability and so on, but also it will provide them with aesthetic emotions and opportunity for physical activities, support their social and sensory development, increase their academic achievement (especially for concepts used in science and mathematics education), and improve their skills in using tools (raking, shovel, etc.). Activities using the principles of permaculture design in school gardens, neighborhoods or balconies of their homes help children to produce healthy food, draw attention to the issue of sustainability, offer solutions to the problems caused by today's excessive consumption and problems in their immediate environment, soil and fertilizer production, improvement of the living spaces of animals, and therefore, it is important to include such activities in the pre-school education stage, which is the most basic stage of education, in order to support their skill development and provide benefits in many other ways. In our country, there are no academic studies in the field of education based on the permaculture approach, especially in pre-school education, but there are some studies that private and public educational institutions at various levels such as preschool, primary school, secondary school, high school have carried out some permaculture projects and designed school gardens for permaculture design. This situation clearly showed that awareness in the field of education has started, but there is still a great deficiency in terms of academic studies. With this study, it is aimed to fill the gap in the literature and to create a resource for researchers and educators who want to work on permaculture design, which has recently started to spread in our country, which is still relevant in the world.
\end{abstract}

Keywords: Preschool education, permaculture, sustainability. 


\section{Giriş}

İnsanoğlunun varoluşundan bugüne doğayı sınırsız bir kaynak olarak görüp kirletmesi çevre sorunlarının ortaya çıkmasına yol açmıştır. Hızla artan nüfus ve tükenmekte olan doğal kaynaklar, insanların yeni çözüm arayışlarına girmelerine sebep olmuştur. Bu çözüm arayışları insanları sürdürülebilir çevre düzenlemelerine yönlendirmiştir. Sürdürülebilir çevre düşünceleri, var olan kaynakların gelecek nesillerin de ihtiyaçlarını karşılayabilecek şekilde; özenli, planlı ve düzenli kullanılmasıdır. Doğal kaynakların sınırlı olduğu ve tükenebileceği gerçeğinin bilincinde olarak çevrenin korunması ve bu durumun süreklilik arz etmesi gerekmektedir (Şimşek Bayar, 2016).

İklim değişikliğinin olumsuz etkileri, toprak bozulması, kirlilik, ormansızlaşma, hızlı yapılaşma gibi sürdürülebilir olmayan şartlar hayat kalitesini giderek bozmaktadır (Parlak, 2018). Son zamanlarda gelecek nesillerin de ihtiyaçlarının sağlanabilmesi için sürdürülebilirliğe ve sürdürülebilir kalkınmaya verilen değer artmaktadır. Bu nedenle her alanda sürdürülebilirlik için amaçlar belirlenmekte ve bu amaçlar doğrultusunda stratejiler geliştirilmektedir (Gurlaş, 2017).

Sorunlara çözüm bulmak adına çevreye olumsuz etkilerin azaltıldığı, kaynakların bilinçli ve verimli kullanıldığı daha sağ lıklı yaşam alanlarının oluşturulması için son zamanlarda doğanın döngüsünü önemseyen ekolojik sistem temelli yaklaşımlar ve yöntemler geliştirilmeye çalışılmakta ve denenmektedir. İnsanın doğa ile uyumlu bir çevrede yaşamını sürdürülebilir kılacak ilkeler geliştirmeyi amaçlayan ve şehir planlamalarında değeri hızla artan düşüncelerden biri de permakültürdür (Najafidashtapeh ve Hamamcioğlu, 2018).

Permakültür, çeşitli ilke ve uygulamaların kullanıldığı onarıcı insan yerleşimleri oluşturmayı hedefleyen bir tasarım bilimi olarak açıklanmaktadır. Permakültür, doğayı, doğadaki ilişkileri, bağlantıları temel alır ve ana teması toprak üretimidir. Ayrıca permakültür, doğal ve tarımsal ekosistemler ile her ölçekteki yerleşim alanlarının onarımında ve inşaat, enerji, atık yönetimi, okul müfredatı, ticari işletmeler vb. de karar verme süreçlerinin şekillendirilmesinde kullanılmaktadır (Aksoy, 2018).

Günümüzde dünyanın birçok yerinde okullar permakültür ilkelerini temel almaya ve bunları bir permakültür tasarımı oluşturmak için okul 
bahçelerinde uygulamaya çalışmaktadırlar (Öztürk, 2020). Okul bahçesine kompostlama, malç kullanma gibi organik yöntemlerin kullanıldığı ve kimyasalların kullanılmadığ yerel ekoloji daha çeşitli olacak ve burası böcekler, kuşlar ve diğer hayvanlar için yaşam alanı sunacaktır. Doğal ortamları keşfederek ve öğrenerek, öğrenciler doğa ile nasıl etkileşim kuracaklarını öğrenirler ve çevrenin karmaşık çeşitliliğine tanık olabilirler. Araştırmalar, bahçecilik gibi bir tür dış mekân eğitim faaliyetine katılan öğrencilerin çevre için daha fazla değer ve takdire sahip olduklarını göstermiştir. Bahçe düzenlemesine dayalı etkinliklere katılarak öğrenciler, doğal sistemler konusundaki anlayışlarını artırarak çevre için daha yüksek bir değere sahip olabilirler (Blair, 2009; Waliczek ve Zajicek, 1999: Akt. Mullins, 2011).

Okul öncesi dönem, çocuklarda merak duygusu ve öğrenme isteğinin yoğun olduğu bir dönemdir. Bu açıdan okul öncesi dönem, çocukların yaşadıkları çevreyi tanıma, çevrelerine dair olumlu tutum geliştirme, çevre sorunlarına karşı farkındalık ve çevre koruma bilinci kazanmalarında oldukça önemlidir (Uludağ, Karademir ve Cingi, 2017). $\mathrm{Bu}$ nedenle çocuklara erken yaşlarda verilecek permakültür eğitimi; onların doğa ve çevre sorunlarına ve bu sorunlara çözüm yolları bulma, çevreye duyarlı olma, ekolojik sürdürülebilirlik gibi konularda çocukları bilinçlendirebilecektir. Ayrıca permakültür eğitimi çocuklara estetik duygular kazandırma, fiziksel aktivite imkânı sunma, sosyal ve duygusal gelişimlerini destekleme, akademik (özellikle fen, matematik eğitiminde kullanılan kavramlara yönelik) başarılarını yükseltme, tarım araçları tanıma ve kullanma (tırmık, kürek, vb.) becerilerini arttırma yoluyla gelişim alanlarını da çok yönlü olarak destekleyebilir.

\section{Permakültürün Tanımı ve Tarihçesi}

Permakültür (Latince: permanere sürmek, devam etmek; cultura tarm), doğadaki insan yerleşimlerini, doğal ekosistemlerden örneklenen ziraat uygulamaları ve sürdürülebilirlik görüşüne göre uygulayan bir ekolojik tasarmm anlayışıdır (Graham, 1992; 2004: Akt. https://tr.wikipedia.org/wiki/Permakültür). Permakültürün güncel bir tanımı da 'doğada bulunan kalıpları ve ilişkileri taklit ederken, aynı zamanda 
yerel ihtiyaçların sağlanması için bol miktarda yiyecek, lif ve enerji sağlayan bilinçli olarak tasarlanmış peyzajlar olarak yapılabilmektedir (Holmgren, 2007: Akt. Mullins, 2011). Ayrica Ferguson ve Lovell (2014) günümüzde, "permakültür" terimini, birbirinden ayrı fakat birbiriyle bağlantıll; bir tasarım metodolojisi, bir yöntem ve teknik havuzu, sosyal bir hareket ve sosyal bir felsefe şeklinde dört farklı anlamı barındırdığını ifade etmiştir (Akt. Üsküplü ve Polat, 2019).

Mollison (2009), 'Permakültüre Giriş' adlı kitabında permakültür kelimesinin sadece kalıcı tarımı ifade etmediğini, aynı zamanda kalıcı kültürün de bir daralması olduğunu, çünkü kültürlerin sürdürülebilir bir tarımsal temel ve arazi kullanım etiği olmadan uzun süre yaşayamayacağını belirtmiştir. Permakültür tasarım sisteminin, ekolojik olarak sağlam ve ekonomik olarak uygulanabilir, kendi ihtiyaçlarını karşılayan, istismar etmeyen veya kirletmeyen ve dolayısıyla uzun vadede sürdürülebilir sistemler yaratmak için sürdürülebilir bir yaşam tarzı önerdiğini vurgulamıştır (Akt. Kılıç, 2014).

Permakültür, 70'lerde Bill Mollison ve lisansüstü öğrencisi David Holmgren tarafından sürdürülebilir yaşam ve arazi kullanımı için bir tasarım sistemi olarak geliştirilmiştir. Bu alanda yaptıkları çalışmalar sonucunda permakültür felsefesini bir dizi inanç ve yol gösterici ilkeyle özetlemişlerdir. Böylece ortaya çıkan fikirlerini; permakültür tasarımcıları, öğretmenleri ve aktivistleri, 30 yılı aşkın süredir dünyaya yaymaktadırlar. Avustralya'da, peyzajdan okul bahçelerine, pasif güneş enerjisi tasarımından kompost tuvaletlere ve etik yatırımlardan çiftçi pazarlarına kadar günümüzün ana akım çevre çözümlerinin çoğunda permakültürün kavramsal bir etkisi görülmektedir (Holmgren, 2011).

\section{Permakültürün Etik İlkeleri}

Permakültürün ilkeleri Bill Mollison'un üç etik ilkesini temel alarak oluşturulduğundan öncelikle etik ilkeler aşağıda açıklanmıştır:

Yeryüzene Özen Gösterme: Bu ilke, tüm canlı ve cansız şeylerle (topraklar, türler ve çeşitleri, atmosfer, ormanlar, mikro habitatlar, hayvanlar ve sular) ilgilenmek olarak tanımlanan permakültürün temel etiğidir. 
Ínsanlara Özen Gösterme: Yeryüzüne özen göstermek; g1da, barınma, eğitim, tatmin edici istihdam ve keyifli insan sözleşmesi gibi temel ihtiyaçlarımızın karşılanması için insanlara özen göstermeyi de gerektirir.

Fazlalığın İadesi: Bu ilke, temel ihtiyaçlarımızı karşıladıktan ve sistemlerimizi elimizden gelen en iyi şekilde tasarladıktan sonra, başkalarının bu amaca ulaşmasına yardımcı olmak için etkimizi ve enerjimizi genişletebileceğimiz anlamına gelir (Mollison, 2009: Akt. Kılıç, 2014).

\section{Permakültür İlkeleri}

Ekolojik sistemlerin kurgulanması konusunda tasarımclara yol göstermesi için Bill Mollison'un öğrencisi David Holmgren'in "Principles and Pathways Beyond Sustainability" (2001) kitabındaki başlıklara göre on iki tane permakültür ilkesi tanımlanmıştır (Öcal, 2020).

Arayüzlerden Faydalanma (Kenar Etkileri): Kenarlar farklı ekolojik yapılara sahip alanlardır. İki ekolojik alan arasındaki sınırda verimlilik artar (toprak/su, orman/çayır, nehir ağzı/okyanus, tarla/meyve bahçesi) çünkü her iki sistemin kaynakları da kullanılabilir durumdadır (Mollison, 2011: Akt. Öcal, 2020).

Çeşitliliği Sağlama: Karışık bir sistemdeki verim toplamının, düzenliliğin hâkim olduğu monokültürel bir sisteme göre çok daha yüksek olacağ 1 belirtilmektedir (Mollison, 2011: Akt. Öcal, 2020).

Küçük ve Yavaş Çözümler Kullanma: Büyük çapta, enerji tüketen kapsamlı sistemler yerine küçük çapta, enerjiyi tutumlu kullanan, yoğunlaştırılmış sistemler planlanması hedeflenmektedir (Mollison, 2015: Akt. Gurlaş, 2017).

Birleştirme: Bu ilke her işlevin çok sayıda eleman ile desteklenmesinin ve birleştirilmesinin gerektiğini belirtmektedir (Hemenway, 2015: Akt. Gurlaş, 2017). 
Örüntülere Göre Tasarım Yapma: Sahadaki doğal elemanlar topografya, bitki örtüsü, su yolları gibi ayrı ayrı düşünülmesinden ziyade, birlikte oluşturdukları örüntü yapısı kavranırsa tasarıma doğru bir başlangıç yapılacağı anlatılmaktadır (Parlak, 2018).

Atık Üretmeme: Reddetmek, azaltmak, yenilemek, onarmak ve geri kazanmak ilkelerini kullanarak kaynakların tüketiminde savurganlığ 1 önleme amaçlamaktadır (Holmgren, 2002: Akt. Gurlaş, 2017).

Yenilenebilir Kaynakları Kullanma: Burada temel hedef güneş, rüzgâr, hidroelektrik, dalga enerjisi vb. gibi yenilenebilir enerji kaynaklardan faydalanmaktır (Gurlaş, 2017).

Geri Bildirime Dayanarak Kendi Kendini Yöneten Sistemler Kurma: İnsan davranışlarının negatif sonuçları ile karşılaşıldığında yeni sistemler veya çözümlere yönelmektir (Parlak, 2018).

Enerji Yakalama ve Depolama: Fosil yakıtlar, güneş ve rüzgâr enerjisi gibi enerjileri yakalayıp depolamayı; doğal ve beşerî sermayeyi oluşturacak birikimleri ve yatırımları içermektedir (Gurlaş, 2017).

Verim Alma: Doğal kaynaklardan yakalanan ve depolanan enerjiyi etkili bir biçimde kullanarak canlılar için her seviyede bir sistem dizayn etmek ve bu sistemi sürdürüp daha fazla enerji depolamayı ifade eder (Gurlaş, 2017).

Gözlem ve Etkileşim: İyi bir dizaynın, dikkatli gözlem ve düşünceli etkileşimle tasarımın çıkış kaynağının insanlar ve doğa ile arasındaki özgür ve uyumlu ilişki ağına ve biçimlerine bağlı olduğunu belirtmektedir (Holmgren, 2002: Akt. Gurlaş,2017).

Değişime Yaratıcı Bir Şekilde Yantt Verme: Bu ilke permakültürdeki sorun çözümdür felsefesiyle hareket ederek yeni duruma yaratıcı bir şekilde sistemi uyarlamayı ve bunu sistemin yararına döndürmeye çalışmanın gerekliliğini anlatır (Parlak, 2018). 


\section{Eğitimde Permakültür}

Canlı bir laboratuvar olarak doğa, doğal dünya ile bağlantı kurarken çocuğun ilgisini çeker. Soyut kavramların sınıf müfredatına daha uygun hale gelmesine izin verir. Çocuklar öğrenmek ve büyümek için duyusal uyarıma ve materyallerin manipülasyonuna ihtiyaç duyar- kendilerine söylenenlerle değil, deneyim yoluyla öğrenirler. Bugün birçok çocuğun hayatında eksik olan şey, yaratıcı oyun, sorgulama ve derinlemesine düşünme fırsatlarıyla zenginleştirilmiş doğal ortamlardır (Landy, 2018).

Bir okul bahçesi permakültür ilkeleri ve etiği kullanılarak oluşturulduğunda alan sürdürülebilir olacak ve bu nedenle okul bahçesinde uzun vadeli bir değişiklik olacaktır. Permakültür tasarım ilkelerini çocukların istekleriyle birleştirerek, ekolojik olarak çeşitli, sürdürülebilir ve çocuklara hitap eden bir okul bahçesi tasarımı yapılabilir. Bu şekilde inşa edilmiş bir okul bahçesine sahip olmak, çocukların doğal alanlarla etkileşime girmelerinden elde ettikleri faydaları en üst düzeye çıarma potansiyeline sahiptir. Bir bahçede çocukların istediği temel unsurların belirlenmesi, öğrenciler tarafından yapılan bahçe çizimleri çalışmasıyla yapılabilir. Bu öğeler daha sonra permakültür tasarım ilkeleriyle birleştirilerek bir okul için bahçe tasarımı elde edilebilir. Bir okul bahçesi oluştururken bu iki yönün bütünleştirilmesi sürdürülebilir, çocuklara çekici ve doğal alanlardan elde edilen faydaları en üst düzeye çıkarma potansiyeline sahip bir alan ile sonuçlanacaktır (Mullins, 2011).

Praetorius (2006), 12. Sınıfa kadar çocuklarla düzenlediği permakültür bahçe çalışmasını bir gıda üretim alanından daha fazlası olarak ifade etmektedir. Bu alanın çocukların keyifli bir ortamda konuşmak, oyun oynamak, gözlemlemek, meditasyon yapmak ve çalışmak için bir araya gelebilecekleri sıcak bir yer olduğunu belirtmektedir. Bir okul oldukları için, doğal çevreye uyacak ve dikkat çeken bir açık hava sınıfı yaratmanın önemli olduğunu hissettiklerini söylemektedir. Permakültür ilkelerini tasarımın temeli olarak kullandığımızda, doğa ile birlikte hareket edip ilerleyerek bizlerin de doğanın bir parçası olduğumuzu ve onun dişında hayatta kalamayacağımız için onunla uyumlu hareket etmemiz gerektiğini bizlere hatırlatacağını çalışmasında vurgulamaktadır. 
Lebo ve Eames (2015), yürüttükleri çalışmalarında ortaokul öğrencilerinin bilime ve sürdürülebilir öğrenmeye yönelik tutumlarını iyileştirmek için permakültürün sürdürülebilir gida üretimi yönüne odaklanmışlardır. Araştırmanın bulguları, sürdürülebilir gıda üretiminin hem öğretmen hem de öğrenciler üzerinde olumlu etkileri olduğunu göstermiştir. Öğrenciler bahçede fen öğrenmenin daha eğlenceli olduğunu söylemiş ayrıca, test sonuçları öğrencilerin fen kavramlarının sürdürülebilir öğrenmeyle göreliliğini öğrendiklerini ortaya koymuştur. $\mathrm{Bu}$ nedenle, öğrenciler tohum türleri ve çimlenme, toprak ve biyolojik çeşitlilik gibi belirli bilim kavramlarını daha etkili bir şekilde tanımlamışlardır.

Öztürk (2020), Teksas'ta yürüttüğü çalışmasında permakültürü içeren entegre bir müfredat tasarımının, öğretmen adaylarının ilkokul sınıflarında fen müfredatı öğretme anlayışları ve inançları üzerindeki etkililiğini incelemiştir. Permakültür, gıda üreten bitkilerden oluşan bir orman ekosistemini tasarlama pratiğini içeren uygulamasının kavramsal çerçevesini fen öğretmenlerinin fen müfredatının çoğunu entegre etmek için kullanabileceğini belirtmektedir. Araştırmada öğretmen adaylarına permakültür ve birçok kavramının eyalet bilim standartlarıyla uyumlu hale getirilmesi hakkında bilgi verilmiş ve permakültür hakkındaki inançlarındaki değişiklikleri ile permakültür kavramlarını fen ders planlarına dahil etme yetenekleri değerlendirilmiştir. Bulgular, öğretmen adaylarının kendi kendine yeten bir tasarım sistemi olarak permakültür ve toprak, bitkiler, hayvanlar ve mikroorganizmalar gibi gida ormanındaki bileşenler hakkındaki bilgilerinde artışlar yaşadıklarını göstermektedir. Ayrıca, bu çalışmanın bulguları, okul bahçelerinde bir yiyecek ormanı tasarlamanın ilkokullarda fen kavramlarını birleştirmenin etkili bir yolu olabileceğini göstermektedir.

Ülkemizde permakültür yaklaşımına dayalı eğitim alanında özellikle de okul öncesi eğitimde akademik çalışmalara rastlanmamıştır ancak, okul öncesi, ilkokul, ortaokul, lise gibi çeşitli düzeydeki özel ve kamuya ait eğitim kurumlarının bazı permakültür içerikli projeler yaptıkları ve okul bahçelerini permakültür tasarımına yönelik dizayn ettikleri çalışmalar bulunmaktadır. Bu durum eğitim alanında farkındalığın başladığını fakat buna rağmen akademik çalışmalar açısından büyük bir eksikliğin olduğunu açı bir şekilde göstermiştir. 


\section{Okul Öncesi Eğitimde Permakültür Uygulama Örnekleri}

Okul öncesi dönemde çocukların hayatlarının merkezinde çoğunlukla evleri vardır ve oyun yerleri de genellikle eve yakın mesafedeki yerlerdir. Ev ve bahçe onların değer verdikleri dünyalarıdır. Çünkü çocuklar yakın ve bilinebilir bir dünya ile etkileşimde olmak isterler ve çocuklardan uzaktaki ekosistemlerle ve çevresel sorunlarla ilgilenmelerini istemek onları sevdikleri, kendilerini güvende hissettikleri peyzajlarından uzaklaştırmaya neden olur. Bu duruma neden olmamak adına çocukların kendi bulundukları flora, fauna ve özellikleri tanımaları için çaba gösterilmeli ve başlangıç yeri olarak da okulun arkasındaki koruluk, mahallenin sokakları, dükkanları olmalıdır. Ancak çocuklar çoğunlukla dışarı çıkarılmadan, su birikintilerini incelemeden, yağmur suyu toplamadan, küçük peyzajlar oluşturmadan ya da dereleri takip etmeden bilgileri teorik olarak öğrenirler (Sobel, 2014).

Permakültür tasarımı ile insanın doğayla uyum içinde yaşamasının amaçlandığı düşünüldüğünde çocuklara da permakültür ilkelerine dayalı bahçe etkinlikleri sunarak onları yaşadıkları bölgeden uzaklaştırmadan (örneğin okul bahçelerinde yapılacak etkinliklerle) uygulamalı bir permakültür eğitimine giriş yapmak mümkündür. Ancak permakültür tasarımı oldukça detaylı ve işlevsel uygulamaları (okul binasının kendi enerjisiyle ısınması, aydınlanması, gri suyunu-siyah suyunu arıtabilmesi, atıklarını geri kazanabilmesi vb.) gerektirdiğinden okul öncesi dönemde çocuklarla okullarda öğretmenler ya da evlerde aileleriyle gelişimlerine uygun permakültür ilkelerine yönelik etkinler planlanıp uygulanabilmektedir. Bu etkinliklere örnek olarak;

- atıklarla ilgili geri dönüşüm çalışmaları (atıkların ayrıştırılması),

- kompost yapımı (bitkisel ve hayvansal atıklardan organik gübre elde etme),

- bahçede yerel tohumlarla ekim yapma (yerel tohumların korunması, çoğaltılması vb.),

- tohum topları hazırlama (çeşitli tohumların yoğrulan çamurla top haline getirilip uygun zaman ve koşullarda toprağa atılması), 
- yağmur suyu biriktirip değerlendirme (bu su ile bahçenin sulanması ya da kurulacak bir kümesteki hayvanların içme suyunun karşılanması vb.),

- malç yapma (toprak üzeri saman, ağaç kıymıkları, talaş gibi bitki artıklarıyla doğal örtü oluşturma),

- böcek oteli (böcekler için yaşam alanları oluşturma),

- hayvan yemlikleri oluşturma,

- çanta bahçeleri yapmak (bir torba, teneke, taşlar ve biraz toprak kullanarak küçük alanlarda bahçe oluşturmak),

- okul bostanları oluşturma (bahçenin durumuna uygun çözümler kullanılarak mevsimine göre sebzelerin, salata yeşilliklerinin, şifalı bitkilerin yetiştirilmesi,),

- solucan, kuş, kümes hayvanlarının dışkılarından gübre elde edip bunu bahçede kullanmak,

- gıda ormanı (yer örtücü bitkiler, bodur çalılar ve farklı yükseklikteki ağaçlardan oluşan türlerin arasına meyve ağaçlarının dikilmesi) oluşturma,

- yükseltilmiş sebze yatakları (toprakta dört tarafı çevrili izole yükseltilmiş bir dolgu toprak alanı oluşturulup bu alanda üretim yapılması) hazırlama vb. verilebilir.

\section{Sonuç ve Öneriler}

Çocuklarla okul bahçelerinde, mahallelerindeki yeşil alanlarda veya evlerinin balkonlarında permakültür tasarım ilkelerini kullanarak yapılacak uygulamaların çocukların sağlıklı gida üretme, sürdürülebilirlik konusuna dikkat çekme, günümüzdeki aşırı tüketime ve yakın çevrelerindeki sorunlardan dolayı oluşan olumsuzluklara çözümler sunabilme, toprak ve gübre üretme, hayvanların yaşam alanlarını iyileştirme, çocukların gelişim alanlarındaki becerilerinin desteklenmesi ve daha pek çok açıdan fayda sağlaması adına eğitimin en temel basamağ olan okul öncesi eğitim basamağına dahil edilmesi önemlidir. Yapılan araştırmalar incelendiğinde ülkemizde permakültür konusunda; mimarlık, peyzaj mimarlığı, sosyo-kültürel çalışmalar, işletme yönetimi, yönetim ve organizasyon, turizm, şehir ve bölge planlama, gastronomi ve mutfak sanatları, çevre bilimleri alanlarında çalışmalara rastlanmış ancak 
eğitim alanında özellikle de okul öncesi eğitimde permakültürü içeren akademik bir çalışmaya rastlanmamıştır. Yapılan bu çalışmayla literatürdeki eksikliğin giderilmesi ve dünyada güncelliğini koruyan permakültür tasarımı üzerine çalışma yapmak isteyen araştırmacılara ve eğitimcilere kaynak oluşturması amaçlanmaktadır.

Alanyazındaki eksiklikler göz önüne alındığında, permakültürün çocuklara sunacağı sayısız faydalarını düşünerek hem çocuklar hem de erken çocukluk eğitimi veren kişilere ve ebeveynlere temel oluşturması ve yol göstermesi açısından bu alanda akademik çalışma ve uygulamaların yapılmasının alanyazına zenginlik katacağı düşünülmektedir. 


\title{
EXTENDED ABSTRACT
}

\section{Preschool Education and Permaculture}

\author{
Sedef Çağlar Kabacık- Ebru Deretarla Gül \\ MONE-Çukurova University
}

Permaculture is explained as a science of design that aims to create restorative human settlements using various principles and practices. Permaculture is based on nature, relations and connections in nature, and its main theme is soil productivity. In addition, permaculture is used in shaping decision-making processes of the restoration of natural and agricultural ecosystems and residential areas of all sizes and in construction, energy, waste management, school curriculum, commercial enterprises, etc. (Aksoy, 2018).

Today, schools in many parts of the world are trying to take the principles of permaculture as a basis and apply them in school gardens to create a permaculture design (Öztürk, 2020). Including a garden with organic methods such as composting, mulch, and no chemicals in the schoolyard, the local ecology will be more diverse and offer habitat for insects, birds and other animals. By exploring and learning natural environments, students learn how to interact with nature and can witness the complex diversity of the environment. Studies have shown that students participating in some type of outdoor education activity, such as gardening, have greater value and appreciation for the environment. By participating in activities based on gardening, students can have a higher value for the environment by increasing their understanding of natural systems (Blair, 2009; Waliczek ve Zajicek, 1999: Akt. Mullins, 2011).

Preschool period is a period in which children's curiosity and desire to learn are intense. In this respect, the preschool period is very important for children to get to know the environment they live in, to develop a positive attitude about their environment, to gain awareness of environmental problems and environmental protection (Uludağ, Karademir, \& Cingi, 2017). For this reason, permaculture education to be given to children at an early age; will be able to raise the awareness of children on issues such as their nature and environmental problems and 
finding solutions to these problems, being sensitive to the environment, and ecological sustainability. In addition, permaculture education provides children with aesthetic emotions, providing opportunities for physical activity, supporting their social and emotional development, increasing their academic achievements (especially for concepts used in science and mathematics education), improving their skills in recognizing and using agricultural tools (raking, shovel, etc.) can also support their fields in a versatile way.

Preschool children often have their homes at the center of their lives, and play places are usually close to home. The home and garden are their worlds they value. Because children want to interact with a close and knowable world, and asking them to deal with distant ecosystems and environmental problems causes them to distract them from the landscapes they love and feel safe. In order not to cause this situation, efforts should be made for the children to get to know the flora, fauna and characteristics they are in, and the woodland behind the school, the streets of the neighborhood, and the shops should be the starting point. However, children often learn the information theoretically without being taken outside, examining puddles, collecting rainwater, creating small landscapes or following streams (Sobel, 2019).

Considering that the purpose of permaculture design is for people to live in harmony with nature, it is possible to enter into an applied permaculture education without removing them from the area where they live by offering garden activities based on permaculture principles. However, since permaculture design requires very detailed and functional applications (heating of the school building with its own energy, lighting, treatment of gray water and black water, recovery of waste, etc.), activities for permaculture principles can be planned and implemented in pre-school period with teachers at schools or at home with their families. Examples of these activities are recycling activities related to waste (separation of waste), composting (obtaining organic fertilizer from plant and animal waste), sowing with local seeds in the garden (preserving local seeds, propagation, etc.), preparing seed balls (various seeds are formed into balls with kneaded mud and disposal to the soil in time and conditions), collecting and utilizing rain water (irrigating the garden with this water or meeting the drinking water of the 
animals in a poultry to be established, etc.), making mulch (creating natural cover with plant residues such as straw, wood chips, sawdust on the soil), insect hotel (creating habitats for insects), creating animal feeders, obtaining fertilizer from the droppings of worms, birds, poultry and using it in the garden, etc.

Using the principles of permaculture design in school gardens, neighborhoods or balconies of their homes, children can produce healthy food, draw attention to the issue of sustainability, offer solutions to the negativities caused by today's excessive consumption and problems in their immediate surroundings, produce soil and fertilizers, improve the living spaces of animals, It is important to include them in the pre-school education stage, which is the most basic stage of education, in order to support their skills in development areas and to provide benefits in many other ways. When earlier studies about permaculture in our country are examined, one might find research studies in architecture, landscape architecture, socio-cultural studies, business administration, management and organization, tourism, city and regional planning, gastronomy and culinary arts, environmental sciences, but no academic study involving permaculture has been found in the field of education, especially in preschool education. With this study, it is aimed to fill this void in the literature and to create a resource for researchers and educators who want to work on permaculture design, which is still relevant in the world.

Considering the shortcomings in the literature, it is thought that academic studies and practices in this field will enrich the literature in terms of providing a basis and guidance for both children and early childhood education providers and parents, considering the numerous benefits that permaculture will offer to children.

\section{Kaynakça / References}

Aksoy, U. (2018). İzmir Akdeniz Akademisi'nden. Meltem İzmir Akdeniz Akademisi Dergisi, 4, 94-95.

Gurlaş, F. (2017). Alternatif turizm için sürdürülebilir dengeli skor kartın permakültür ekolojik köy ve çiftliklerinde uygulanması: Pastoral vadi örneği. (Yüksek lisans tezi). Karadeniz Teknik Üniversitesi Sosyal Bilimler Enstitüsü İsletme Anabilim Dal, Trabzon. 
Holmgren, D. (2011). Weeds or wild nature: A permaculture perspective. Plant Protection Quarterly, 26(3), 92-97.

Kılıç, M. A. (2014). Rebuilding the relationship ignored between children and naturalbuilt environment through scool garden designed by permaculture method. (Master's thesis). İzmir Institute of Technology, İzmir.

Landy, C. (2018). The state of outdoor education in northeast tennessee: preschool teacher attitudes toward outdoor education. Electronic Theses and Dissertations. Paper 3453. htps://dc.etsu.edu/etd/3453

Lebo, N. and Eames, C. (2015). Cultivating attitudes and trellising learning: A permaculture approach to science and sustainability education. Australian Journal of Environmental Education, 31(1), 46-59.

Mullins, M. (2011). Designing a school garden space that emphasizes children's wants and uses permaculture design methods. Environmental Studies Undergraduate Student Theses.

Najafıdashtape, A., and Hamamcıoğlu, C. (2018). Sorumlu üretim ve tüketim bağlamında permakültür ve kentsel açık ve yeşil alan ilişkisi. Mimarlık Bilimleri ve Uygulamalar Dergisi, 3(1), 1-17.

Ozturk, S. (2020). An investigation of preservice teachers' understanding of and beliefs about teaching science in the Ec-6 classrooms using permaculture. (Master's thesis). Texas State University, ABD.

Öcal, Y. (2020). Kentsel yerleşimlerde permakültür tasarım potansiyeli: Burdur Karamanlı örneği. (Yüksek lisans tezi). Gazi Üniversitesi, Fen Bilimleri Enstitüsü, Çevre Bilimleri Anabilim Dalı, Ankara.

Parlak, N. N. (2018). Ekolojik peyzaj tasarımı ve permakültür yaklaşımı. (Yüksek lisans tezi). İstanbul Üniversitesi, Fen Bilimleri Enstitüsü, Peyzaj Mimarlığı Anabilim Dalı, İstanbul.

Praetorius, P. (2006) A permaculture school garden. Green teacher, 78(6).

Sobel, D. (2014). Ekofobiyi Aşmak Doğa Eğitiminde Kalbin Yeri. (Çev: İlknur Urkun Kelso). İstanbul: Yeni İnsan Yayınevi. Çeviri tarihi 2019.

Şimşek Bayar, M. (2016). Sürdürülebilir yaşam tasarımı permakültür: İstanbul'a ilişkin ön değerlendirme. (Yüksek lisans tezi). Mimar Sinan Güzel Sanatlar Üniversitesi, Fen Bilimleri Enstitüsü, Şehir ve Bölge Planlama Anabilim Dalı, İstanbul.

Uludağ, G., Karademir, A. H., ve Cingi, M. A. (2017). Okul öncesi öğretmen adaylarının sürdürülebilir çevreye ilişkin davranış düzeylerinin incelenmesi. Mehmet Akif Ersoy Üniversitesi Eğitim Fakültesi Dergisi, 1(41), 120-136. 
Üsküplü, E. M., ve Polat, Z. (2019). Permakültür çocuk oyun alanları. Journal of Adnan Menderes University, Agricultural Faculty, 16(2), 245-252.

URL-1. (https://tr.wikipedia.org/wiki/Permakültür). (Erişim Tarihi: 12.11.2020).

\section{Kaynakça Bilgisi / Citation Information}

Çağlar Kabacık, S. ve Deretarla Gül, E. (2021). Okul öncesi eğitim ve permakültür. OPUS-Uluslararası Toplum Araştırmaları Dergisi, 18(Eğitim Bilimleri Özel Sayıs1), 5140-5156. DOI: 10.26466/opus.910266. 